\title{
Salicylate acutely stimulates 5'- AMP-activated protein kinase and insulin-independent glucose transport in rat skeletal muscles.
}

\section{$\operatorname{AUTHOR}(\mathrm{S}):$}

Serizawa, Yasuhiro; Oshima, Rieko; Yoshida, Mitsuki; Sakon, Ichika; Kitani, Kazuto; Goto, Ayumi; Tsuda, Satoshi; Hayashi, Tatsuya

\section{CITATION:}

Serizawa, Yasuhiro ... [et al]. Salicylate acutely stimulates 5'-AMP-activated protein kinase and insulin-independent glucose transport in rat skeletal muscles.. Biochemical and biophysical research communications 2014, 453(1): 81-85

\section{ISSUE DATE:}

2014-10-10

URL:

http://hdl.handle.net/2433/192273

\section{RIGHT:}

(c) 2014 Elsevier Inc.; この論文は出版社版でありません。引用の際には 出版社版をご確認ご利用ください。; This is not the published version. Please cite only the published version. 
Salicylate acutely stimulates 5'-AMP-activated protein kinase and insulin-independent glucose transport in rat skeletal muscles

Yasuhiro Serizawa, Rieko Oshima*, Mitsuki Yoshida, Ichika Sakon, Kazuto Kitani, Ayumi Goto, Satoshi Tsuda, Tatsuya Hayashi

Laboratory of Sports and Exercise Medicine, Graduate School of Human and Environmental Studies, Kyoto University, Kyoto, 606-8501, Japan

*Address correspondence to:

Rieko Oshima, M.S.

Laboratory of Sports and Exercise Medicine, Graduate School of Human and Environmental Studies, Kyoto University, Yoshida-nihonmatsu-cho, Sakyo-ku, Kyoto, 606-8501, Japan

Telephone, Fax:+81-75-753-6640, E-mail: oshima.rieko.37r@st.kyoto-u.ac.jp

E-mail: tatsuya@kuhp.kyoto-u.ac.jp (T. Hayashi) 


\section{ABSTRACT}

Salicylate (SAL) has been recently implicated in the antidiabetic effect in humans. We assessed whether 5'-AMP-activated protein kinase (AMPK) in skeletal muscle is involved in the effect of SAL on glucose homeostasis. Rat fast-twitch epitrochlearis and slow-twitch soleus muscles were incubated in buffer containing SAL. Intracellular concentrations of SAL increased rapidly $(<5 \mathrm{~min})$ in both skeletal muscles, and the $\mathrm{Thr}^{172}$ phosphorylation of the $\alpha$ subunit of AMPK increased in a dose- and time-dependent manner. SAL increased both AMPK $\alpha 1$ and AMPK $\alpha 2$ activities. These increases in enzyme activity were accompanied by an increase in the activity of 3-O-methyl-D-glucose transport, and decreases in ATP, phosphocreatine, and glycogen contents. SAL did not change the phosphorylation of insulin receptor signaling including insulin receptor substrate 1 , Akt, and p70 ribosomal protein S6 kinase. These results suggest that SAL may be transported into skeletal muscle and may stimulate AMPK and glucose transport via energy deprivation in multiple muscle types. Skeletal muscle AMPK might be part of the mechanism responsible for the metabolic improvement induced by SAL.

Keywords: Salicylate, 5'-AMP-activated protein kinase, Glucose transport, Insulin signaling, Skeletal muscle, Diabetes mellitus

\section{Abbreviations:}


SAL, salicylate; T2D, type 2 diabetes mellitus; AMPK, 5'-AMP-activated protein kinase; KRB, Krebs-Ringer bicarbonate buffer; DNP, 2,4-dinitrophenol;

AICAR:

5-aminoimidazole-4-carboxamide-1- $\alpha$-D-ribonucleoside; IRS1, insulin receptor substrate 1; p70S6K, p70 ribosomal protein S6 kinase; GLUT4, glucose transporter 4; AMPK $\alpha 1$;, $\alpha 1$-containing AMPK complex; AMPK $\alpha 2$, a2-containing AMPK complex; $3 \mathrm{MG}, \quad 3-O$-methyl-D-glucose; $\mathrm{PCr}$, phosphocreatine; SE, standard error. 


\section{Introduction}

Salicylate (SAL), a willow bark product, has been used as an anti-inflammatory agent since ancient times. SAL induces systemic anti-inflammatory effects by suppressing cyclooxygenase, resulting in decreased production of proinflammatory mediators such as prostaglandins [1].

Interestingly, a number of clinical studies have suggested that SAL stimulates metabolic processes and improves glucose homeostasis in humans. Goldfine et al [2] demonstrated that a 14-week oral SAL treatment (salsalate 3.0-4.0 g/day) significantly improved glycemic control in patients with type 2 diabetes (T2D). The mean changes in the hemoglobin A1c level were $-0.36 \%$ at $3.0 \mathrm{~g} /$ day, $-0.34 \%$ at $3.5 \mathrm{~g} /$ day, and $-0.49 \%$ at $4.0 \mathrm{~g} /$ day compared with the placebo. More recently, Goldfine et al [3] demonstrated that long-term (48 weeks) oral SAL treatment (salsalate $3.5 \mathrm{~g} /$ day) significantly improved glycemic control in people with T2D. The mean hemoglobin A1c level after 48 weeks was $0.37 \%$ lower in the SAL group than in the placebo group.

We hypothesized that 5'-AMP-activated protein kinase (AMPK) in skeletal muscle plays a pivotal role in the antidiabetic effect of SAL. AMPK is a metabolite-sensing protein kinase and is acutely activated by energy-depriving stimuli in skeletal muscle such as exercise (contraction). Although Hawley et al [4] first reported that AMPK is phosphorylated in mouse soleus muscle 90 min after an intraperitoneal injection of SAL, to our 
knowledge, no study has provide fundamental evidence of AMPK activation in skeletal muscle. Thus, the primary aim of the current study was to determine whether SAL is taken up into skeletal muscle cells and, if so, whether it stimulates AMPK by altering the energy status. We examined two different types of isolated rat skeletal muscles: fast-glycolytic epitrochlearis [5] and slow-oxidative soleus muscles [6]. 


\section{Materials and Methods}

\subsection{Animals}

Male Sprague Dawley rats weighing 150 g (Shimizu Breeding Laboratories, Kyoto, Japan) fed a standard chow and water ad libitum were randomly divided into experimental groups after an overnight fast. The experimental protocols were approved by Kyoto University Graduate School of Human and Environmental Studies, and Kyoto University Radioisotope Research Center.

\subsection{Muscle preparation in vitro}

Muscle incubation was conducted as we have previously described [7]. Epitrochlearis and soleus muscles were isolated after cervical dislocation. The muscles were attached to an incubation apparatus and preincubated in Krebs-Ringer bicarbonate buffer (KRB) containing $2 \mathrm{mM}$ pyruvate for $40 \mathrm{~min}$. Muscles were then transferred to buffer containing various concentrations (0-10 mM) of SAL (sodium salicylate) for 30 min or buffer containing $5 \mathrm{mM}$ SAL for up to $60 \mathrm{~min}$. Muscles were also incubated in buffer containing 0.5 mM 2,4-dinitrophenol (DNP) for $10 \quad \min$ or $2 \quad \mathrm{mM}$ 5-aminoimidazole-4-carboxamide-1- $\alpha$-D-ribonucleoside (AICAR) for $30 \mathrm{~min}$ for maximal stimulation of AMPK, or $1 \mu \mathrm{M}$ insulin for $30 \mathrm{~min}$ for maximal stimulation of insulin signaling. The muscles samples were either used for SAL transport and glucose transport measurements, or they were frozen in 
liquid nitrogen for other assays.

\subsection{Western blotting}

Western blot analysis was performed as we have previously described [7]. Frozen muscle was homogenized in buffer containing 1\% Triton X-100, 20 $\mathrm{mM}$ Tris $\mathrm{HCl}$ (pH 7.4), $250 \mathrm{mM}$ sucrose, $50 \mathrm{mM} \mathrm{NaCl}, 2 \mathrm{mM}$ dithiothreitol, 50 $\mathrm{mM} \mathrm{NaF}, 5 \mathrm{mM}$ sodium pyrophosphate, $50 \mathrm{mg} / \mathrm{l}$ trypsin inhibitor, $4 \mathrm{mg} / \mathrm{l}$ leupeptin, $0.1 \mathrm{mM}$ benzamidine, $0.5 \mathrm{mM}$ phenylmethylsulfonyl fluoride, and $1 \mathrm{mM} \mathrm{Na}_{2} \mathrm{VO}_{4}\left(\right.$ Buffer A) at $4^{\circ} \mathrm{C}$. The homogenate was centrifuged at 16,000 $\mathrm{g}$ for $40 \mathrm{~min}$ at $4^{\circ} \mathrm{C}$. Aliquots of the supernatant $(10 \mu \mathrm{g}$ of protein) were separated by SDS-PAGE and transferred to a polyvinylidene difluoride membrane. The membrane was blocked with skim milk and then incubated overnight at $4^{\circ} \mathrm{C}$ with primary antibodies. The primary antibodies were to AMPK $\alpha$ subunit (\#2532; Cell Signaling Technology, Danvers, MA, USA), phosphospecific AMPK $\alpha$ subunit Thr172 (\#2531; Cell Signaling Technology), phosphospecific insulin receptor substrate 1 (IRS1) Tyr612 (44-816G. Life Technologies, Carlsbad, CA, USA), IRS1 (06-248, Millipore, Billerica, MA, USA), phosphospecific Akt Ser473 (\#9271; Cell Signaling Technology), Akt (\#9272, Cell Signaling Technology), phosphospecific p70 ribosomal protein S6 kinase (p70S6K) Thr 389 (\#9205, Cell Signaling Technology), p70S6K (\#9202, Cell Signaling Technology), glucose transporter 4 (GLUT4) (4670-1704, Biogenesis, Poole, UK), and actin (\#4968, Cell Signaling Technology). The membrane was then incubated with anti-rabbit IgG. Protein signals were 
developed using enhanced chemiluminescence (Millipore) and detected with ImageCapture G3 (Liponics, Tokyo, Japan).

\subsection{Isoform-specific AMPK activity assay}

AMPK comprises the catalytic $\alpha$ and regulatory $\beta$ and $\gamma$ subunits, and there are two distinct $\alpha$ subunits: $\alpha 1$ and $\alpha 2$ [8]. The kinase activities of $\alpha 1$-containing AMPK complex (AMPK $\alpha 1)$ and $\alpha 2$-containing AMPK complex $(\mathrm{AMPK} \alpha 2)$ were measured as we have previously described [7]. Frozen muscles were homogenized in Buffer A, and the resultant supernatants (100 $\mu \mathrm{g}$ protein) were incubated with either anti- $\alpha 1$ or $-\alpha 2$ antibody [7] and Protein A Sepharose beads (Amersham Biosciences, Uppsala, Sweden) at $4^{\circ} \mathrm{C}$ overnight. The beads were subjected to the kinase reaction using the SAMS peptide as a substrate. The kinase activity was expressed as incorporated ATP per min per immunoprecipitated protein.

\subsection{SAL transport and glucose transport assay}

SAL transport was measured using the double-isotope $([7-14 \mathrm{C}]$ salicylic acid and $\mathrm{D}^{-}\left[1^{-3} \mathrm{H}(\mathrm{N})\right]$ mannitol) method. Muscles were preincubated and then incubated in $\mathrm{KRB}$ containing $5 \mathrm{mM}\left[7^{-14} \mathrm{C}\right]_{\text {salicylic }}$ acid $(0.3 \mu \mathrm{Ci} / \mathrm{ml}$, American Radiolabeled Chemicals, St. Louis, MO) and $1 \mathrm{mM}$ $\mathrm{D}^{-}\left[1^{-3} \mathrm{H}(\mathrm{N})\right]$ mannitol $(1.5 \mu \mathrm{Ci} / \mathrm{ml}$, American Radiolabeled Chemicals $)$ at $37^{\circ} \mathrm{C}$ for up to $15 \mathrm{~min}$. Muscles were then incubated in $1 \mathrm{M} \mathrm{NaOH}$ at $80^{\circ} \mathrm{C}$ for 10 min. Digestates were neutralized with $1 \mathrm{M} \mathrm{HCl}$, centrifuged at 20,000 $g$ for 3 
min, and the radioactivity in the supernatant was measured by a scintillation counter. The intracellular space was determined as described [9], and the intracellular SAL concentration was calculated. 3- $O$-Methyl-D-glucose (3MG) transport was measured using the double-isotope $\left(\left[{ }^{3} \mathrm{H}\right] 3 \mathrm{MG}\right.$ and $\mathrm{D}^{-}\left[1^{-14} \mathrm{C}\right]$ mannitol) method, as we have previously described [7]. The transport activity was expressed as 3MG taken up per intracellular space per hour.

\subsection{ATP, phosphocreatine (PCr), and glycogen assay}

ATP and PCr contents were measured enzymatically as we have described previously [10]. Glycogen content was measured using a glucose assay reagent (Glucose CII Test, Wako, Osaka, Japan) as we have previously described [11].

\subsection{Statistical analysis}

Data are expressed as mean \pm standard error (SE). Differences between two groups were compared with Student's $t$ test. Multiple means were analyzed using one-way ANOVA followed by post hoc comparison with Tukey's or Dunnett's test. $\mathrm{P}<0.05$ was considered significant. 


\section{Results}

\subsection{Effects of SAL on AMPK $\alpha$ subunit Thr ${ }^{172}$ phosphorylation and AMPK activity in skeletal muscles}

The Thr ${ }^{172}$ residue of the $\alpha$ subunit is the stimulatory phosphorylation site of AMPK [12]. We examined the phosphorylation status in both muscles. The dose-response study of AMPK phosphorylation showed significant increases by 2.4- and 2.7-fold in epitrochlearis muscle at concentrations of 5 and $10 \mathrm{mM}$ of SAL (30 min), and by 1.5-, 2.1-, and $2.2^{-}$fold in soleus muscle at concentrations of 1,5 , and $10 \mathrm{mM}$ of SAL (30 min), respectively (Fig. 1A). The time-course study showed that $5 \mathrm{mM}$ of SAL significantly phosphorylated AMPK after as little as 5 min in soleus and 15 min in epitrochlearis muscles (Fig. 1B). SAL did not change the total amount of AMPK. SAL (5 mM, 30 min) increased the activity of both AMPK $\alpha 1$ and AMPK $\alpha 2$ by $4.1^{-}$and 3.6 -fold in epitrochlearis muscle, and by $2.1^{-}$and 2.4 -fold in soleus, respectively (Fig. 1C).

\subsection{SAL uptake in skeletal muscles}

To our knowledge, no study has shown that SAL is taken up into skeletal muscle tissue. We found that the intracellular concentration of SAL increased rapidly in both epitrochlearis and soleus muscles in a time-dependent manner (Fig. 2A). The intracellular concentration of SAL was $3.1 \pm 0.2 \mathrm{mM}$ in epitrochlearis and $1.8 \pm 0.1 \mathrm{mM}$ in soleus at 15 min after 
the start of exposure to buffer containing 5 mM SAL.

\subsection{Effects of SAL on glucose transport and energy status in skeletal muscles}

AMPK is thought to act as a signaling molecule leading to an increase in insulin-independent glucose transport elicited by energy-depriving stresses in skeletal muscle $[13,14]$. The increased AMPK activity by SAL (5 mM, 30 min) was associated with a 2.7-fold increase in 3MG transport in epitrochlearis muscle and a 4.2-fold increase in soleus muscle (Fig. 2B) compared with the basal conditions. Correspondingly, the contents of ATP, PCr, and glycogen were significantly lower in SAL-treated muscle samples than in the basal muscle samples for both epitrochlearis and soleus (Table 1).

\subsection{Effects of SAL on insulin signaling molecules in skeletal muscles}

The pharmacological inhibitor of oxidative phosphorylation, DNP, significantly phosphorylated AMPK in both muscles (Fig. 2C). The AMPK activator AICAR strongly phosphorylated AMPK in epitrochlearis and slightly phosphorylated AMPK in soleus, as we have previously reported [15]. By contrast, insulin did not phosphorylate AMPK in either muscle. Similar to DNP and AICAR, SAL did not increase the phosphorylation of insulin signaling molecules including IRS1, Akt, and p70S6K. SAL did not affect GLUT4 or actin content in either muscle. 


\section{Discussion}

It has been suggested that skeletal muscle AMPK is involved in a variety of acute and chronic metabolic activation processes $[16,17,18,19]$ such as insulin-independent glucose transport, fatty acid oxidation, glycogen regulation, expression of the GLUT4 glucose transporter, stimulation of peroxisome proliferator-activated receptor $\gamma$ coactivator $1 \alpha$, mitochondrial biogenesis, and enhanced insulin sensitivity. Besides exercise (contraction), there are a number of physiologically relevant stimuli of skeletal muscle AMPK, such as adipokines including leptin and adiponectin, antidiabetic drugs such as metformin and thiazolidinediones, and functional foods and their natural components [18,20,21]. In our earlier studies, we demonstrated that Morus alba leaf extract [22], caffeine [10], berberine [15], Coptidis rhizoma extract [23], and caffeic acid [24], all of which have been implicated as having antidiabetic properties, acutely (<30 min) promoted AMPK activity in isolated rat skeletal muscles.

SAL has been shown to uncouple oxidative phosphorylation [1,25]. The SAL-induced decrease in ATP concentration has been documented in Drosophila melanogaster tissue culture (SL2) cells [26] and human neutrophils [27]. However, as far as we know, the present study is the first to demonstrate the ability of SAL to decrease the energy status in skeletal muscle. Interestingly, Hawley et al [4] showed that SAL is a direct AMPK activator that binds to the same site as the synthetic AMPK activator A-769662, which causes allosteric AMPK activation and inhibition of 
dephosphorylation of the $\alpha$ subunit $\mathrm{Thr}^{172}$. They also demonstrated that SAL promoted AMPK phosphorylation and activity in the absence of energy deprivation (an increase in ADP: ATP ratio) in HEK-293 cells [4]. Thus, SAL may stimulate AMPK via both energy-dependent and energy-independent processes in skeletal muscle.

Hawley et al [4] found that oral SAL treatment for 2 weeks decreased fasting glucose concentration and improved insulin sensitivity and glucose tolerance in both the wild-type and AMPK $\beta 1$ subunit knockout mice in a high fat diet-induced insulin-resistant condition. This seems to suggest that the effect of SAL on glucose metabolism is AMPK independent. However, Western blot analysis of rat tissues has revealed that the $\beta 1$ subunit is most abundant in the liver and that little exists in skeletal muscle, whereas the $\beta 2$ subunit is most abundant in skeletal muscle and little exists in the liver [28] In fact, the $\beta 1$-knockout mice had decreased AMPK activity in the liver but not in skeletal muscle [29]. Therefore, it is still possible that skeletal muscle AMPK plays an important role in mediating the effects of SAL on glucose homeostasis.

The typical plasma concentration of SAL for clinical use is $0.95-1.9 \mathrm{mM}$, but the plasma concentration of free SAL falls in the range of $<0.25 \mathrm{mM}$ because of plasma protein binding of 80-90\% [1]. Although we showed that the intracellular concentration of SAL increased rapidly after exposure to SAL (Fig. 2A), it is unlikely that a single oral dose of SAL is enough to induce substantial metabolic activation in skeletal muscle. As speculated from the 
finding of Goldfine et al [2] who demonstrated improved glycemic control after a 14-week SAL treatment in people with T2D, repeated SAL administration might contribute to a clinically relevant activation of AMPK in skeletal muscle.

An advantage of using an isolated muscle preparation is that we could eliminate the confounding effects elicited by systemic administration of SAL. In particular, we considered the possibility that SAL inhibits IKK $\beta$, an enzyme that is responsible for the activation of nuclear factor $\kappa$ [30], and that evokes direct and/or indirect metabolic changes in skeletal muscle [31]. We used Western blotting to examine the inhibitory effect of SAL on IKK $\alpha / \beta$ phosphorylation in isolated muscles. However, because of the very low phosphorylation in the basal samples, we could not determine whether IKK phosphorylation decreased after SAL treatment in either muscle (data not shown).

In summary, we report here for the first time that SAL was transported into muscle cells, where it increased both AMPK $\alpha 1$ and $\alpha 2$ activities, and glucose transport, and decreased muscle energy status. These effects occurred in both fast- and slow-twitch skeletal muscles. We propose that skeletal muscle AMPK is involved in the mechanism leading to the SAL-induced activation of glucose metabolism. 


\section{Author contributions}

YS, RO and TH designed the experiments; YS, RO, MY, IS, KK, AG and ST performed experiments; YS and RO analyzed data; YS, RO and TH wrote the manuscript.

\section{Grants}

This study was supported by research grants from the Japan Society for the Promotion of Science (TH, 23617009), Urakami Foundation for Food and Food Culture (TH), the Foundation for Dietary Scientific Research (TH), and Asahi Group Foundation (TH), Vascular Disease Research Foundation (TH), and Research Fellowship of the Japan Society for the Promotion of Science for Young Scientists (AG, ST).

\section{Conflict of Interest}

The authors state no conflict of interest.

\section{Acknowledgments}

We are grateful to the Kyoto University Research Center for Low Temperature and Materials Sciences and the Radioisotope Research Center 
of Kyoto University for their support. We thank Licht Miyamoto and Tatsuro Egawa for valuable discussion. 


\section{Figure and table legends}

Fig. 1 SAL phosphorylates the $\alpha$ subunit $\mathrm{Thr}^{172}$, and stimulates both AMPK $\alpha 1$ and AMPK $\alpha 2$ activities in skeletal muscles.

(A) Epitrochlearis (EPI) and soleus (SOL) muscles were incubated with SAL (0-10 mM) for $30 \mathrm{~min}$. The lysate was analyzed by Western blotting. Values are means $\pm \mathrm{SE} ; \mathrm{n}=6 .{ }^{* *} \mathrm{P}<0.01$ vs. basal condition. Representative immunoblots are shown. (B) Muscles were incubated in the absence (basal) or presence of $5 \mathrm{mM}$ SAL for 0-60 $\mathrm{min}$. The lysate was analyzed by Western blotting. $\mathrm{n}=6-10 .{ }^{* *} \mathrm{P}<0.01$ and ${ }^{*} \mathrm{P}<0.05$ vs. basal. Representative immunoblots are shown. (C) Muscles were incubated with or without SAL (5 $\mathrm{mM}$ ) for $30 \mathrm{~min}$, and $\alpha$-isoform-specific AMPK activity was measured. Values are means $\pm \mathrm{SE} ; \mathrm{n}=6 .{ }^{*} \mathrm{P}<0.01$ vs. basal condition.

Fig. 2 SAL is transported into isolated skeletal muscles and stimulates 3MG transport without affecting insulin signaling in skeletal muscles.

(A) Muscles were incubated with $5 \mathrm{mM}$ SAL for 0-15 min. Intracellular SAL concentration was measured at each time point. Values are means $\pm \mathrm{SE} ; \mathrm{n}=$ 6-7. ${ }^{* *} \mathrm{P}<0.01$ vs. 0-min group. \# $\mathrm{P}<0.01$ vs. 5-min group. (B) Muscles were incubated with or without SAL ( $5 \mathrm{mM})$ for $30 \mathrm{~min}$, and $3 \mathrm{MG}$ transport was measured. Values are means $\pm \mathrm{SE} ; \mathrm{n}=8-9 . * * \mathrm{P}<0.01$ vs. basal condition. (C) Muscles were incubated with or without SAL (5 mM) for $30 \mathrm{~min}$, AICAR $(2 \mathrm{mM})$ or insulin $(1 \mu \mathrm{M})$ for $30 \mathrm{~min}$, or DNP $(0.5 \mathrm{mM})$ for $10 \mathrm{~min}$, and 
analyzed by Western blotting. Representative immunoblots are shown.

\section{Table 1}

SAL decreases the energy status in skeletal muscles.

Muscles were incubated with or without $5 \mathrm{mM}$ SAL for $30 \mathrm{~min}$. ATP, PCr, and glycogen contents were measured. Values are expressed as $\mathrm{nmol} / \mathrm{mg}$ wet weight. Values are means $\pm \mathrm{SE} ; \mathrm{n}=5 .{ }^{* *} \mathrm{P}<0.01$ vs. basal condition. 


\section{References}

[1] R. Amann, B.A. Peskar, Anti-inflammatory effects of aspirin and sodium salicylate, Eur J Pharmacol 447 (2002) 1-9.

[2] A.B. Goldfine, V. Fonseca, K.A. Jablonski, L. Pyle, M.A. Staten, S.E. Shoelson, T.-T.D.S. Team, The effects of salsalate on glycemic control in patients with type 2 diabetes: a randomized trial, Ann Intern Med 152 (2010) 346-357.

[3] A.B. Goldfine, V. Fonseca, K.A. Jablonski, Y.D. Chen, L. Tipton, M.A. Staten, S.E. Shoelson, T. Targeting Inflammation Using Salsalate in Type 2 Diabetes Study, Salicylate (salsalate) in patients with type 2 diabetes: a randomized trial, Ann Intern Med 159 (2013) $1-12$.

[4] S.A. Hawley, M.D. Fullerton, F.A. Ross, J.D. Schertzer, C. Chevtzoff, K.J. Walker, M.W. Peggie, D. Zibrova, K.A. Green, K.J. Mustard, B.E. Kemp, K. Sakamoto, G.R. Steinberg, D.G. Hardie, The ancient drug salicylate directly activates AMP-activated protein kinase, Science 336 (2012) 918-922.

[5] R. Nesher, I.E. Karl, K.E. Kaiser, D.M. Kipnis, Epitrochlearis muscle. I. Mechanical performance, energetics, and fiber composition, Am J Physiol 239 (1980) E454-460.

[6] R.B. Armstrong, R.O. Phelps, Muscle fiber type composition of the rat hindlimb, Am J Anat 171 (1984) 259-272.

[7] T. Toyoda, T. Hayashi, L. Miyamoto, S. Yonemitsu, M. Nakano, S. Tanaka, K. Ebihara, H. Masuzaki, K. Hosoda, G. Inoue, A. Otaka, K. Sato, T. Fushiki, K. Nakao, Possible involvement of the alpha1 isoform of 5'AMP-activated protein kinase in oxidative stress-stimulated glucose transport in skeletal muscle, Am J Physiol Endocrinol Metab 287 (2004) E166-173. 
[8] D. Stapleton, K.I. Mitchelhill, G. Gao, J. Widmer, B.J. Michell, T. Teh, C.M. House, C.S. Fernandez, T. Cox, L.A. Witters, B.E. Kemp, Mammalian AMP-activated protein kinase subfamily, J Biol Chem 271 (1996) 611-614.

[9] D.A. Young, J.J. Uhl, G.D. Cartee, J.O. Holloszy, Activation of glucose transport in muscle by prolonged exposure to insulin. Effects of glucose and insulin concentrations, $\mathrm{J}$ Biol Chem 261 (1986) 16049-16053.

[10] T. Egawa, T. Hamada, N. Kameda, K. Karaike, X. Ma, S. Masuda, N. Iwanaka, T. Hayashi, Caffeine acutely activates 5'adenosine monophosphate-activated protein kinase and increases insulin-independent glucose transport in rat skeletal muscles, Metabolism 58 (2009) 1609-1617.

[11] M. Nakano, T. Hamada, T. Hayashi, S. Yonemitsu, L. Miyamoto, T. Toyoda, S. Tanaka, H. Masuzaki, K. Ebihara, Y. Ogawa, K. Hosoda, G. Inoue, Y. Yoshimasa, A. Otaka, T. Fushiki, K. Nakao, alpha2 Isoform-specific activation of 5'adenosine monophosphate-activated protein kinase by 5-aminoimidazole-4-carboxamide-1-beta-d-ribonucleoside at a physiological level activates glucose transport and increases glucose transporter 4 in mouse skeletal muscle, Metabolism 55 (2006) 300-308.

[12] S.C. Stein, A. Woods, N.A. Jones, M.D. Davison, D. Carling, The regulation of AMP-activated protein kinase by phosphorylation, Biochem J 345 Pt 3 (2000) 437-443. [13] T. Hayashi, M.F. Hirshman, N. Fujii, S.A. Habinowski, L.A. Witters, L.J. Goodyear, Metabolic stress and altered glucose transport: activation of AMP-activated protein kinase as a unifying coupling mechanism, Diabetes 49 (2000) 527-531.

[14] J. Mu, J.T. Brozinick, Jr., O. Valladares, M. Bucan, M.J. Birnbaum, A role for AMP-activated protein kinase in contraction- and hypoxia-regulated glucose transport in 
skeletal muscle, Mol Cell 7 (2001) 1085-1094.

[15] X. Ma, T. Egawa, H. Kimura, K. Karaike, S. Masuda, N. Iwanaka, T. Hayashi, Berberine-induced activation of 5'-adenosine monophosphate-activated protein kinase and glucose transport in rat skeletal muscles, Metabolism 59 (2010) 1619-1627. [16] D.G. Hardie, S.A. Hawley, J.W. Scott, AMP-activated protein kinase--development of the energy sensor concept, J Physiol 574 (2006) 7-15.

[17] N. Fujii, N. Jessen, L.J. Goodyear, AMP-activated protein kinase and the regulation of glucose transport, Am J Physiol Endocrinol Metab 291 (2006) E867-877.

[18] D.G. Hardie, Sensing of energy and nutrients by AMP-activated protein kinase, Am J Clin Nutr 93 (2011) 891S-896.

[19] M. Friedrichsen, B. Mortensen, C. Pehmoller, J.B. Birk, J.F. Wojtaszewski, Exercise-induced AMPK activity in skeletal muscle: role in glucose uptake and insulin sensitivity, Mol Cell Endocrinol 366 (2013) 204-214.

[20] D.G. Hardie, Role of AMP-activated protein kinase in the metabolic syndrome and in heart disease, FEBS Lett 582 (2008) 81-89.

[21] T. Egawa, S. Tsuda, R. Oshima, K. Goto, T. Hayashi, Activation of 5'AMP-activated protein kinase in skeletal muscle by exercise and phytochemicals, J Phys Fitness Sports Med 3 (2014) 55-64.

[22] X. Ma, N. Iwanaka, S. Masuda, K. Karaike, T. Egawa, T. Hamada, T. Toyoda, L. Miyamoto, K. Nakao, T. Hayashi, Morus alba leaf extract stimulates 5'-AMP-activated protein kinase in isolated rat skeletal muscle, J Ethnopharmacol 122 (2009) 54-59.

[23] X. Ma, T. Egawa, R. Oshima, E. Kurogi, H. Tanabe, S. Tsuda, T. Hayashi, Coptidis rhizoma water extract stimulates 5'-AMP-activated protein kinase in rat skeletal muscle, Chin J Nat Med 9 (2011) 215-221. 
[24] S. Tsuda, T. Egawa, X. Ma, R. Oshima, E. Kurogi, T. Hayashi, Coffee polyphenol caffeic acid but not chlorogenic acid increases 5'AMP-activated protein kinase and insulin-independent glucose transport in rat skeletal muscle, J Nutr Biochem 23 (2012) 1403-1409.

[25] A.R. Temple, Pathophysiology of aspirin overdosage toxicity, with implications for management, Pediatrics 62 (1978) 873-876.

[26] N.A. Winegarden, K.S. Wong, M. Sopta, J.T. Westwood, Sodium salicylate decreases intracellular ATP, induces both heat shock factor binding and chromosomal puffing, but does not induce hsp 70 gene transcription in Drosophila, J Biol Chem 271 (1996) 26971-26980.

[27] B.N. Cronstein, M. Van de Stouwe, L. Druska, R.I. Levin, G. Weissmann, Nonsteroidal antiinflammatory agents inhibit stimulated neutrophil adhesion to endothelium: adenosine dependent and independent mechanisms, Inflammation 18 (1994) 323-335.

[28] C. Thornton, M.A. Snowden, D. Carling, Identification of a novel AMP-activated protein kinase beta subunit isoform that is highly expressed in skeletal muscle, J Biol Chem 273 (1998) 12443-12450.

[29] N. Dzamko, B.J. van Denderen, A.L. Hevener, S.B. Jorgensen, J. Honeyman, S. Galic, Z.P. Chen, M.J. Watt, D.J. Campbell, G.R. Steinberg, B.E. Kemp, AMPK beta1 deletion reduces appetite, preventing obesity and hepatic insulin resistance, J Biol Chem 285 (2010) 115-122.

[30] M.J. Yin, Y. Yamamoto, R.B. Gaynor, The anti-inflammatory agents aspirin and salicylate inhibit the activity of I(kappa)B kinase-beta, Nature 396 (1998) 77-80.

[31] M. Yuan, N. Konstantopoulos, J. Lee, L. Hansen, Z.W. Li, M. Karin, S.E. Shoelson, 
Reversal of obesity- and diet-induced insulin resistance with salicylates or targeted disruption of Ikkbeta, Science 293 (2001) 1673-1677. 
Figure 1.

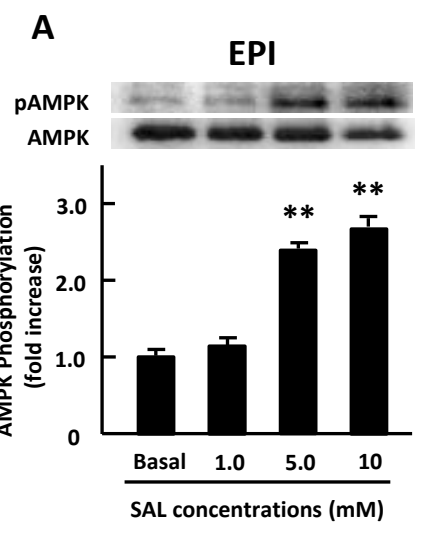

B

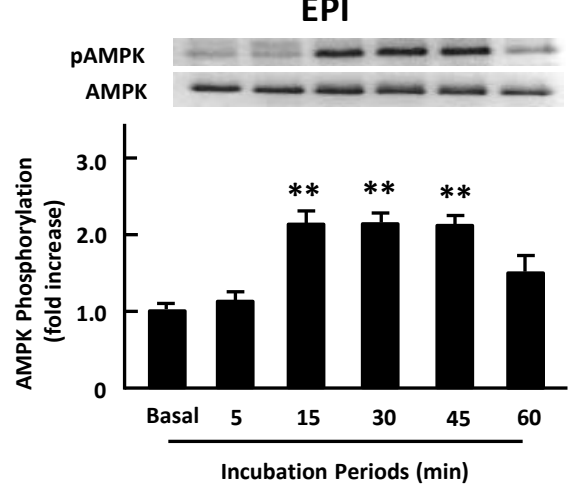

SOL

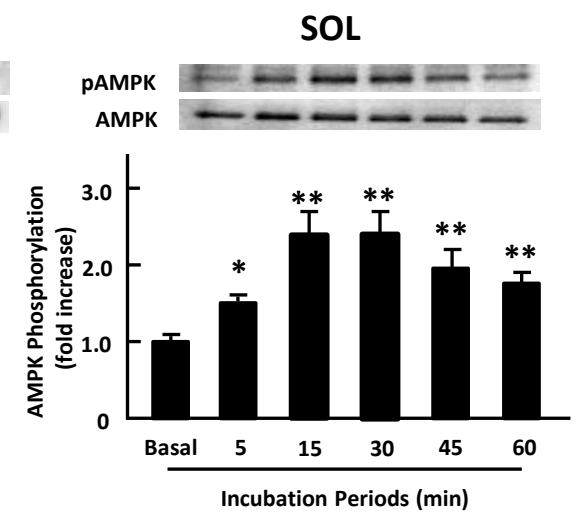

C

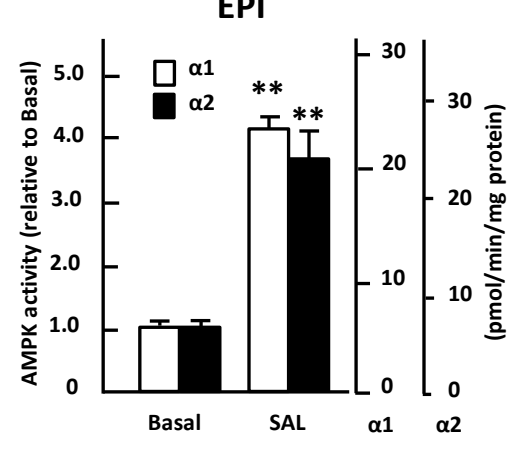

SOL

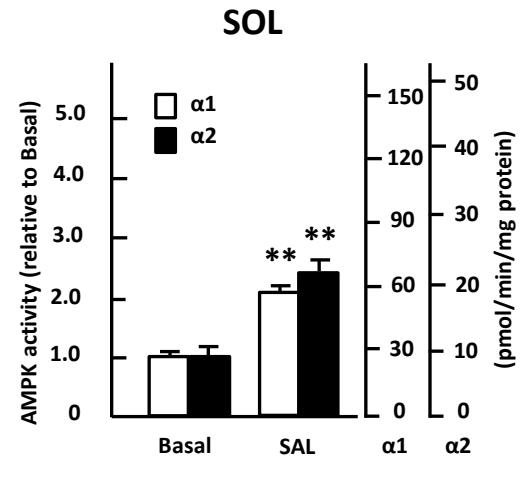

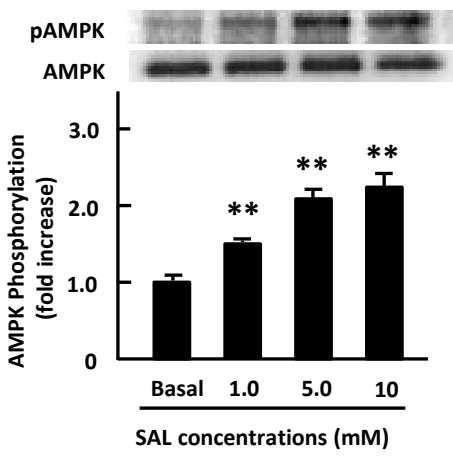


Figure 2.

A

EPI

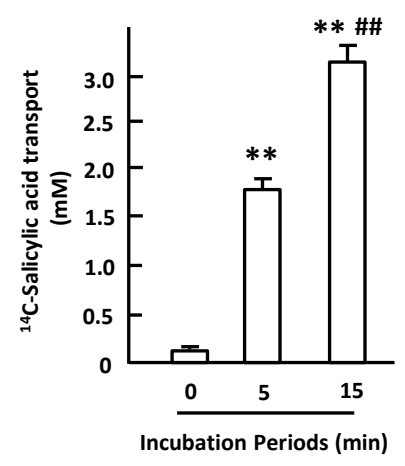

SOL

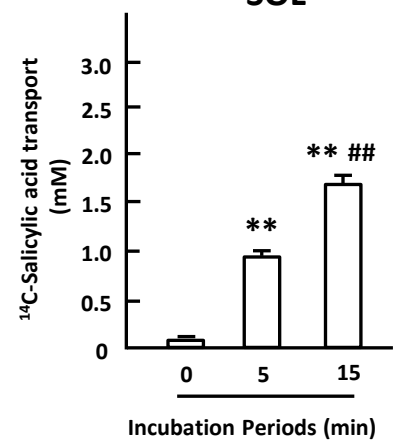

B

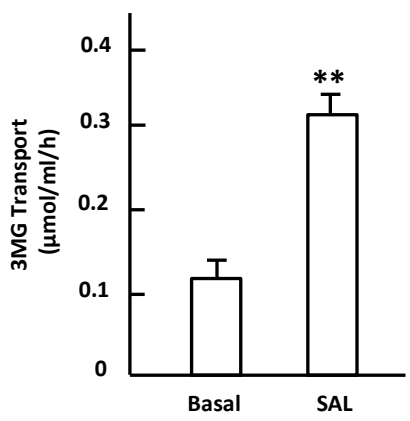

SOL

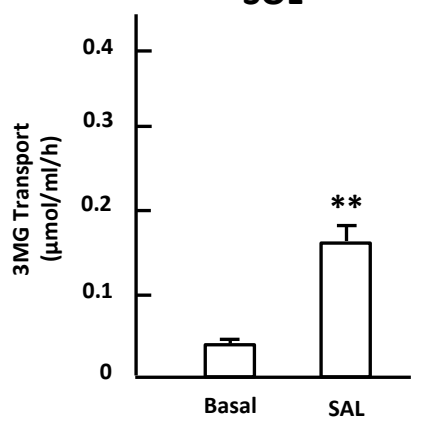

C

EPI

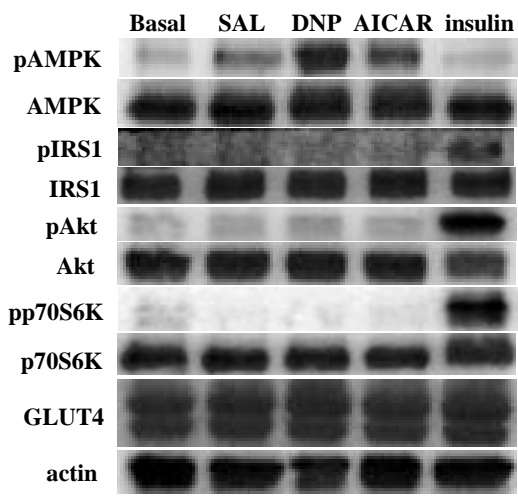

SOL

Basal SAL DNP AICAR insulin

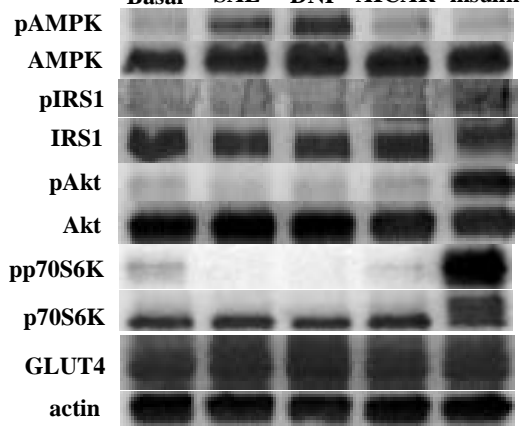


Table 1.

\begin{tabular}{ccrr}
\hline & & \multicolumn{1}{c}{ Basal } & \multicolumn{1}{c}{ SAL } \\
\hline Epitrochlearis & ATP & $4.4 \pm 0.2$ & $2.3 \pm 0.3^{* * *}$ \\
& PCr & $17.2 \pm 0.7$ & $9.7 \pm 0.9^{* * *}$ \\
\multirow{4}{*}{ Soleus } & glycogen & $19.1 \pm 0.8$ & $12.0 \pm 1.1^{* * *}$ \\
& ATP & $2.0 \pm 0.2$ & $1.0 \pm 0.1^{\text {*** }}$ \\
& PCr & $7.6 \pm 0.9$ & $2.5 \pm 0.4^{* *}$ \\
& glycogen & $11.7 \pm 0.3$ & $5.9 \pm 0.4^{* *}$ \\
\hline
\end{tabular}

